\title{
0 desenho como expressão das crianças: a experiência de ser criança e de ser aluno
}

\author{
Drawing as expression of children: the experience of being a child and \\ student
}

\section{Dibujar como expresión de niños: la experiencia de ser niño y estudiante}

\section{Rosana Becker}

Sociedade Educacional de Santa Catarina, Centro Sul Brasileiro de Pesquisa Extensão e PósGraduação, Professora.

https://orcid.org/000-0002-9589-1445

Luiz Martins Junior ${ }^{2}$

Universidade do Estado de Santa Catarina, Programa de Pós-Graduação em Educação, Professor.

https://orcid.org/0000-0002-6026-8338

Jordelina Beatriz Anacleto Uoos ${ }^{3}$

Universidade da Região de Joinuille, Programa de Pós-Graduação em Educação, Professora Titular.

Resumo: 0 presente artigo tem como objetivo compreender como, na relação entre ser criança e ser aluno, a infância expressa as suas vivências na escola. Em função do objetivo delineado, utilizou-se como metodologia a pesquisa etnográfica envolvendo cinquenta e uma crianças de uma turma do primeiro ano do ensino fundamental de uma escola pública do município de Joinville, no Estado de Santa Catarina, em 2018. A aproximação dos pesquisadores com a realidade da escola pesquisada possibilitou conhecer e interpretar o "ponto de vista" das crianças, ficando em evidência que elas distinguem a escola como um lugar com diferentes fazeres, porém, elas desejam ser crianças, num exercício constante de não-submissão.

Palavras-chave: Infância. Ofício de aluno. Ofício de criança. Desenho.

Mestre em Educação pela Universidade do Estado de Santa Catarina; Graduada em Pedagogia pela Associação Catarinense de Ensino.

2 Doutor em Educação pela Universidade do Estado de Santa Catarina; Mestre em Geografia pela Universidade Federal de Santa Catarina.

3 Doutora em Educação pela Pontificia Universidade Católica do Rio Grande do Sul; Mestre em Educação pela Pontifícia Universidade Católica do Rio Grande do Sul. 
Abstract: This article aims to understand how, in the relationship between being a child and being a student, childhood expresses their experiences at school. Due to the objective outlined, ethnographic research involving fifty-one children from a first-year elementary school class at a public school in the city of Joinville, in the state of Santa Catarina, was used as a methodology in 2018. The approach of the researchers to the reality of the researched school made it possible to know and interpret the "point of view" of the children, showing that they distinguish the school as a place with different actions, however, they want to be children, in a constant exercise submission.

Keywords: Childhood. Student craft. Child craft. Drawing.

Resumen: Este artículo tiene como objetivo comprender cómo, en la relación entre ser un niño y ser un estudiante, la infancia expresa sus experiencias en la escuela. Debido al objetivo planteado, se utilizó como metodología la investigación etnográfica que involucró a cincuenta y un niños de una clase de primer año de primaria de una escuela pública de la ciudad de Joinville, en el estado de Santa Catarina, como metodología en 2018. El acercamiento de los investigadores a la realidad de la escuela investigada permitió conocer e interpretar el "punto de vista" de los niños, demostrando que ellos distinguen la escuela como un lugar con diferentes acciones, sin embargo, quieren ser niños, en un ejercicio constante de no sumisión.

Palabras clave: Infancia. Manualidades estudiantiles. Manualidades infantiles. Dibujo.

Recebido em 25 de maio de 2020

Aceito em 2 de fevereiro de 2021

\section{INTRODUÇÃO: CONTEXTUALIZANDO A INUESTIGAÇÃO}

Apresenta-se, neste artigo, o resultado de uma investigação realizada em uma escola pública, que atende estudantes da Educação Básica, situada no município de Joinville, SC, envolvendo cinquenta e uma crianças do $1^{\circ}$ ano do Ensino Fundamental, com o objetivo de compreender como, na relação entre ser criança e ser aluno, a infância expressa as suas vivências na escola.

Considerando a etapa da escolaridade das crianças, bem como a idade, o desenho configurou-se como um instrumento de registro de dados, pois é uma linguagem utilizada pelas crianças e veicula seus modos de pensar e sentir. Assim, o desenho tem, em seus campos teóricos, importantes referências, como Gobbi (2014); Derdyk (2004); Leite (1998); Moreira (2018), entre outros que permitem entendê-lo, no âmbito desta pesquisa, considerando as representações como pano de fundo para estabelecer a relação entre a cartografia e 
a infância, na medida em que tratam do que expressam as crianças de si mesmas e da instituição educativa que frequentam.

A pesquisa se apoia, além dos autores já citados, nos estudos de Faria et al. (2009). As autoras em tela, destacam que devemos assumir como legítimas as diferentes formas de comunicação das crianças, mesmo que os significados que elas atribuem às suas experiências possam ser distintas do universo adulto, no caso específico, na relação criança e professor. Trazendo à tona a questão da infância, especificamente, a de sua educação, o que se colocou num primeiro plano foi a demarcação de seu alcance e de suas fronteiras para consolidar um estudo particularizado na área, com a intenção de enfrentar a seguinte questão: como, na relação entre ser criança e ser aluno, a infância expressa as suas vivências, em uma escola pública?

0 veio metodológico fundamentou-se num paradigma de base qualitativa de caráter etnográfico, por ser o mais adequado ao propósito da investigação, tendo como ponto de partida o objetivo e o problema formulados. Sarmento (2003) escreve que a etnografia visa apreender a vida, tal como ela é cotidianamente conduzida, simbolizada e interpretada pelos atores sociais. Nesse tipo de pesquisa, a análise dos dados gerados foi predominantemente descritiva, porque o estudo centra-se no processo, significado e entendimento do que as crianças produzem expressando as vivências infantis na relação entre ser criança e ser aluno em uma escola. Por isso, foi descrita a caracterização das participantes do processo e das atividades realizadas,-com as crianças, enquanto protagonistas, consideradas como relevantes para a produção e coleta de dados. Seguindo os fundamentos metodológicos da pesquisa qualitativa, a produção e a interpretação dos desenhos das crianças ocorreram em rodas de conversa. As crianças participantes-protagonistas,-foram identificadas com letras maiúsculas do alfabeto latino, garantindo-lhes, assim, o sigilo de suas identidades.

Coerente com a importância de refletir o processo de constituição de ser criança e ser aluno no primeiro ano do Ensino Fundamental, o artigo se estrutura na apresentação do estudo sobre a importância do desenho como produção cultural--na educação das crianças. Na sequência, apresenta o contexto metodológico do estudo, a análise e discussão do processo de empiria e as considerações finais.

\section{OS DESENHOS FALAM: CAPTANDO AS MANIFESTAÇÕES DAS CRIANÇAS}

Para El - um menino de 8 anos de idade, participante da pesquisa, "desenhar é bom para tirar as ideias da cabeça porque sempre que a gente tem uma ideia, a gente 
quer ter ela, aí a gente desenha ela." (informação verbal). A manifestação da criança parecenos muito pertinente para afirmar que o desenho é uma linguagem para a criança, é uma forma de estabelecer comunicação com o mundo, de expressar suas ideias, medos, conflitos, descobertas e alegrias. Desenhando, a criança brinca e, brincando, vai imprimindo as suas marcas no papel, nas paredes, nos muros e calçadas, cartografando, contando, a seu modo, a sua história. Entrar em contato com um recorte dessa história significa, como nos ensina Moreira (2018, p. 95), "ser capaz de arriscar, de entrar no jogo e se deixar contagiar pelo prazer da brincadeira com os traços, as formas e as cores. Reaprender a ver, a se espantar com o que vê [...]" No dizer de Gobbi (2002, p. 200-201), "o desenho é uma representação do mundo, ao mesmo tempo que se constitui como objeto do mundo da representação, revelando-se nas relações universo adulto."

Na abordagem proposta por Arfouillox (1983, p. 128), percebe-se o desenho como um registro mais intenso do que o próprio brinquedo, pois, "ainda mais do que o brinquedo, o desenho da criança fascina. Porque a criança desmancha o seu brinquedo quando o adulto chega, mas o desenho permanece, como as coisas escritas. Ele é um traço, um testemunho." Em cada desenho produzido por uma criança, sujeito datado histórica e culturalmente, há muito a ser visto e percebido, estão ali transbordando sinais, indícios ou pistas que os olhos embaçados dos adultos não aprenderam a ver. $E$ foi isso que nos levou aos questionamentos: como olhar as marcas e os sinais dessa história construida pelas crianças no seu ofício de criança e no ofício de aluno? Como dialogar com as experiências que as crianças têm na escola? 0 que os professores sabem sobre como as crianças vivem o entre-lugar ${ }^{4}-$ criança e aluno?

Nesse sentido, recorremos a Martins (1992), que propõe aos adultos o reconhecimento do desenho enquanto linguagem que pode ser lida. Ela sugere que, talvez, antes (de falarmos sobre os desenhos), tenhamos de nos perguntar sobre o que vemos e lemos de um código que não é composto por letras. Fomos exercitados para isso? Como olhamos e lemos um desenho? Entretanto, Leite (2001, p. 8), em seus estudos, contrapõe-se à ideia de leitura ou escritura da imagem como texto. Para ela, o desenho não é texto para ser lido. Como linguagem visual, tem signos próprios, elementos básicos de apropriação que the são particulares. Ainda segundo a autora, "a sociedade letrada é predominantemente imbuída da supremacia da leitura", e as escolas muito têm colaborado com essa situação, quando, no processo de alfabetização, "deslocam todo o poder do conhecimento para letras, palavras e textos." (LEITE, 2001, p. 8). Mas as crianças, por sua vez, subvertem as normas e regras

4 E um conceito de entrelugar, apropriado da literatura, segundo Silviano Santiago lensaísta, poeta, contista e romancista brasileiro), é aquele exterior com o qual temos de conviver, devemos conviver, e na medida do possível devemos transgredir, para que surja uma voz que tenha certa originalidade, que não seja mera cópia. 
impostas pela escola, encontrando outras formas de se expressar, como desenhar, brincar, cantar e dançar.

Com o objetivo de nos debruçarmos sobre essas outras formas de expressão e/ ou representação das crianças e, na ausência de um novo termo, pareceu-nos significativo chamá-las de cartografia da infância, na ótica dos escritos de Deleuze e Guattari (2011).

Mas por que cartografia? Neste estudo, entendemos por cartografia da infância os desenhos produzidos por meninos e meninas, estudantes de uma escola pública do Ensino Fundamental, por considerarmos que esta concepção abarca a ideia de mapa. É um instrumento de representação, ora silencioso ora concentrado ou ruidoso, individual ou coletivo que, seguido de comentários, risos, ponderações, troca-trocas, vai lentamente sendo transformado em uma gigantesca mapoteca: que fala, denuncia, expressa desejos, que conta sobre um cotidiano ainda desconhecido pelos adultos. Cotidiano este, considerado por muitos como coisa menor, irrelevante, repetitivo. É também um espaço para tornar importante e significativo o que muitas vezes é invisível.

Um dos desafios da investigação refere-se a essa invisibilidade vivida pela criança; no cotidiano da escola; e que não se tornou possível traduzir na totalidade. De acordo com Gusmão (1999),

[...] não se pode conhecer toda a cultura de um grupo ou povo, senão que aspectos dela e nisto reside o desafio no campo do conhecimento tanto quanto no campo das práticas sociais. Nisto reside o desafio de compreendermos que se faz necessário, não apenas estarmos sensiveis à questão da diferença, mas, também e sobretudo, que não sejamos mais analfabetos nas muitas linguagens do social, de modo a fazer-thes as leituras expressas por suas múltiplas falas, imagens, movimentos etc. (GUSMÃ0, 1999, p. 44).

Por outro lado, Arfouilloux (1983), defende que

\footnotetext{
[...] qualquer tentativa de codificação dos sinais icônicos encontra pela frente a multiplicidade e a complexidade das relações contextuais individuais que não permitem distinguir traços pertinentes constantes de uma representação para outra. A semiologia do desenho da criança deve ainda ser feita, mas não é certo que ela seja suscetivel de esgotar toda a sua riqueza de significação, nem mesmo que ela seja possivel (ARFOUILLOUX, 1983, p. 137).
}

Isso nos leva a parafrasear Leite (1998, p. 140), entendendo que cada desenho está impregnado da realidade ali retratada, da sua possibilidade técnica e do entrelaçamento das subjetividades daquele que desenha, daquele que se deixa desenhar e de cada diferente 
contemplador, independentemente de seus tempos cronológicos ou espaços geográficos. "0 desenho pode representar, então, uma possibilidade de compreensão de tempos não linear, que traz implícitos em sua imagem explícita o antes e o depois". Em complementação aos autores citados, Leite (2001, p. 7) afirma que,

[..] contemplando ativamente a representação, isto é, observando e tentando compreender as figuras da imaginação do pintor, tornadas visiveis pelo desenho, pela cor, pela disposição em perspectiva no plano bidimensional pelo jogo de relações entre todas as figuras, nesse grande espaço contínuo, podemos entender um pouco [...], didaticamente seu conteúdo estético. (LEITE, 2001, p. 7).

0 que a criança desenha também é um fenômeno estético, afirma Gusmão (1997), pois foi construído de vivências das crianças na sua singularidade e na sua experiência social. Desta forma, os desenhos das crianças, considerados como representações que deixam falar de si e do outro, são mapas que, em seus traçados, permitem ao observador contemplar e dialogar não só com a dimensão estética, mas, sobretudo, com a poética da cultura infantil. Mapa, registro esse que, com significação própria, fica disponível como uma das "cem linguagens" da criança, no dizer de Malaguzzi (1999). Conforme Pinto e Sarmento (1997):

\footnotetext{
[..] o olhar das crianças permite revelar fenômenos sociais que $\circ$ olhar dos adultos deixa na penumbra ou obscurece totalmente. Assim, interpretar as representações sociais das crianças pode não ser apenas um meio de acesso d̀ infância como categoria social, mas às próprias estruturas e dinâmicas sociais que são desocultadas no discurso das crianças. (PINTO; SARMENT0, 1997, p. 25).
}

Poderíamos ampliar a ideia desses autores no que concerne às diversas formas de expressão das crianças, protagonistas da e na história, quando, ao referir-se a elas, consideram-nas como

\footnotetext{
[...] atores sociais de pleno direito, e não como menores ou como componentes acessórios ou meios da sociedade dos adultos, implica o reconhecimento da capacidade de produção simbólica por parte das crianças e a constituição das suas representações e crenças em sistemas organizados, isto é, em culturas. (PINTO; SARMENTO, 1997, p. 20).
}

Urge, portanto, a necessidade de educar os adultos no sentido de perceber as crianças como atores sociais e de apreender as suas "cem" maneiras de ser e de estar 
no mundo, evitando o risco de reduzir a sua capacidade de expressão apenas à fala, o que empobrece significativamente suas múltiplas linguagens. À luz desse entendimento, focaremos (como se explicitará mais adiante), as análises dos desenhos das crianças com a perspectiva de conhecer o mundo vivido e os ofícios desempenhados por elas. Essas crianças são alunos e alunas de uma escola pública do Ensino Fundamental da rede municipal de ensino da cidade de Joinville/SC.

Ainda na busca de entender seus desenhos e de manifestar nossa crença nas crianças, vistas como desenhistas e falantes, inspiramo-nos em outros teóricos, cujas concepções sobre desenho parecem pertinentes ao estudo. Destacamos a contribuição de Frange (1995), que afirma que

[...] desenhar é desenhar-se! É autofundar-se, é transformar-se: é transfundar-se social e pluridimensionalmente. Desenhar vai além da relação papel - lápis: é além de um nome e de uma denominação. Desenhar é performance visual, não adestramento. Desenhar é edificar singularidades, afetar os outros e se deixar afetar. (FRANGE, 1995, p. 27).

Derdyk (2004, p. 24), artista plástica e pesquisadora sobre a produção do desenho infantil, salienta que "o desenho enquanto linguagem, requisita uma postura global. Desenhar não é copiar formas, figuras. Desenhar objetos, pessoas, situações, animais, emoções, ideias, são tentativas de aproximação com o mundo. Desenhar é conhecer, é apropriar-se." A autora sustenta a concepção de que desenhar e falar são maneiras de interpretar, portanto, o desenho está além de lápis e papel, mas é uma necessidade vital da criança para significar o mundo que a cerca e representar as pessoas e as coisas que ela tem como referência. $\mathrm{Na}$ continuidade das reflexões, essa autora ressalta que o desenho manifesta o desejo da representação, mas, também, o desenho é medo, é opressão, é alegria, é curiosidade, é afirmação, é negação. Ao desenhar, a criança passa por um intenso processo vivencial e existencial (DERDYK, 2004, p. 51). Nesse contexto, Leite (1998), ao inscrever o desenho das crianças como manifestações culturais, considera

\footnotetext{
[...] indiscutivel que cada manifestação artística é um conjunto de linguagens e o desafio de trabalho com a produção cultural infantil está na possibilidade de fazer aflorar sua visão de mundo, não só pelas suas diferenças, pela dimensão crítica, mas também pela dimensão artística do conhecimento. (LEITE, 1998, p. 142).
}

A autora prossegue afirmando que "É esse percurso de ir, vir, nomear, desenhar, olhar, rabiscar, narrar, colorir, cantar, mexer-se que faz com que o sujeito crie, a todo 
instante, o significado do mundo em que se insere e não simplesmente o decalque." (LEITE, 1998, p. 141). Em outro estudo sobre o que e como desenham as crianças, Leite (2001, p. 38) enfatiza que os "desenhos de crianças são possibilidades de transbordamento, de fruição, de jogo, de prazer. São geralmente imitativos e repetitivos, como seus jogos ou as histórias que pedem para escutar de novo. Fazem parte, assim também, de seu processo de constituição de identidade."

Essa citação permite perceber o desenho não somente como uma brincadeira, mas também como um registro histórico, social e cultural. Podemos considerá-lo como:

\begin{abstract}
Narrativas visuais que clamam por uma contemplação ativa, por uma visada diferenciada de nossa parte, a fim de que a narrativa se enlace numa cadeia dialógica. Não são desenhos em desenvolvimento feitos por adultos de amanhã, mas atividades linguageiras de meninos e meninas. Portanto, atividades socioculturais aprendidas na interação com o outro, com o diferente de mim, impregnados de prazer. (LETTE, 1998, p. 38).
\end{abstract}

Assim, inspirados em Leite (1998), consideramos as crianças não como meras receptoras de cultura, mas como sujeitos histórico-contextualizados que, com seu choro, riso, movimento, grito, com sua imaginação, resistência, teimosia, explicitados nos desenhos, acabam criando sua própria cultura, significando seu espaço, inclusive nos limites da escola. Ancoramo-nos no trabalho de Gusmão (1997) que, ao perguntar o que é desenho? responde: "Antes de mais nada, antes de "ser", ele "é", constituindo-se num mecanismo de criação artística, de expressão, de comunicação e estética, que fornece um conjunto de significados cognitivos por meio dos quais as pessoas organizam diferentes culturas, expressam as suas percepções de mundo e de si mesmas como indivíduos e como coletividade.

Para essa autora, os desenhos documentam a realidade vivida pelas crianças e podem ser utilizados por professores e pesquisadores como fonte de reflexão e de transformação dessa realidade. Isto posto, recorremos também à reflexão de Moreira (2018, p. 151) para reafirmar que "desenho é linguagem", o que justifica a opção metodológica pelo desenho como forma de captar as manifestações expressivas das crianças que compõem nossa amostra. A opção pelo desenho infantil enquanto instrumento de pesquisa é um indicador dos "cem modos" de falar da criança, conforme Malaguzzi (1999). 


\section{COSTURANDO OS FIOS QUE FORMAM O CORPO METODOLÓGIICO}

0 eixo temático dessa investigação foram os desenhos construídos pelas crianças da educação infantil na esfera educacional, o que oportunizou a opção por uma metodologia de pesquisa qualitativa, com enfoque na técnica etnográfica, por se tratar de um processo de reflexão e análise minuciosa dos registros narrados pelas crianças e, sobremaneira, de suas expressões retratadas através da textualidade imagética: os desenhos.

Para tanto, toma como metodologia a abordagem qualitativa, visto que ela comporta como um movimento de investigação sobre os processos educacionais e possibilita ao pesquisador entrar no ambiente escolar e registrar as vivências, o cotidiano e o aprendizado que tramam na dinamicidade da sala de aula, considerando as falas das crianças, os seus comportamentos e os seus modos de se expressarem um com o outro e até mesmo com o professor (LARA; MOLINA, 2011). Nessa ocasião, valer-se dos fundamentos da etnografia, em particular, se caracteriza como possibilidade de captar, desvendar e entender as histórias de vidas, o contexto cultural, social e econômico, os sentidos, significados e sentimentos que as crianças expressam durante o seu processo de formação: de ser criança e ser aluno.

As qualidades e potencialidades da pesquisa etnográfica, nesta pesquisa, situamse na fronteira que é determinada entre o ser criança, que fala de si, e o sociocultural, que integra o cotidiano narrado, considerando a forma como cada criança expressa seus pensamentos, saberes, subjetividades e suas experiências, que são influenciadas pelo cotidiano em que vive e atua. Dito por outras palavras, esta pesquisa nos permitiu registrar de forma minuciosa e densa todos os sentidos, as narrativas e manifestações das crianças através dos desenhos numa prática investigativa realizada na sala de aula, que é um espaço de minúcia do pequeno (MATOS, 2011).

Os participantes dessa investigação correspondem a um total de cinquenta e uma crianças. Destas, vinte e seis eram meninos e vinte e cinco eram meninas, com idade entre sete e nove anos. Todas as crianças frequentavam o 1 ano do Ensino Fundamental de uma escola da rede municipal de ensino de Joinville/SC no ano de 2018. Dentro do universo dos cinquenta participantes, foram selecionados, para a composição deste artigo, os desenhos e fragmentos de narrativas de sete crianças, utilizando-se, para tanto, os critérios de representatividade do grupo pesquisado e de pertinência ao objeto de estudo, assim denominadas: E1, E2, E3, E4, E5 e E6.

Conforme a estruturação do caminho investigativo, após a inserção no campo e os procedimentos para a geração de dados sobre os atores e o cenário, iniciou-se a análise e a interpretação de dados. No sentido de responder às questões formuladas, já descritas, 
buscando apreender os significados acerca do que dizem as crianças sobre a experiência de ser criança e de ser aluno, o foco de análise foi o desenho, como expressão das crianças, segundo Bhabha (2005).

Os demais procedimentos, como a entrada no campo, as diversas interações e as rodas de conversa com as crianças e a pesquisadora serviram como pontos convergentes do processo. Para criar laços com as crianças, participamos de diversos momentos e espaços, a saber: o recreio, a sala de aula, as aulas de artes e educação física, os momentos de entrada e de saída da escola. À medida que a análise e a interpretação se desenvolviam, cotejavam-se as fontes, em face da grande quantidade de informações e a riqueza de dados, valendo-se da técnica de análise de conteúdo conforme proposto por Barros (1990).

Na primeira etapa foi realizada a pré-análise, isto é, a análise textual, quando as expressões mais utilizadas pelas crianças foram destacadas, o que só foi possível com auxílio das notas de observação redigidas nas situações de interação entre criança e pesquisadora. Na segunda etapa, realizamos o cotejamento da empiria com o referencial teórico, operandose com os processos de codificação, classificação e categorização. Entretanto, com o devido cuidado para que, os ofícios de criança e de aluno não fossem tratados separadamente, pois o propósito da investigação consistia em desvelar de que maneira as distintas relações emergem da complexa interação entre papéis e funções do ser criança e do ser aluno.

\section{PASSAGENS DA IMAGEM: O RETRATO QUE ME FAÇO TRAÇO- A-TRAÇO}

Com base no exposto até aqui, destacam-se alguns desenhos dos participantes no contexto já descrito, no sentido de refletir as representações expressas pelas crianças, ressaltando os sentidos, os significados que se desdobram na trajetória da formação do ser criança e ser aluno. Nos desenhos das crianças, as representações incidem sobre os brinquedos que são, por excelência, os maiores amigos e companheiros das crianças nas suas infâncias (KISHIMOTO, 1998). Tentar compreender essas manifestações, exige que nos debrucemos sobre os recursos e os artefatos, associando as condições de produção, para identificar como esse fenômeno está relacionalmente produzido e que elementos materiais compõem a vida social dessas crianças.

Isso faz repensar as relações que estão envolvidas nessa constituição do ser criança. Importa assinalar os fatores de socialização das crianças pelos adultos, principalmente pelas pressões institucionalizadoras dos cotidianos infantis e pelo mercado 
para a infância, desde a indústria dos brinquedos às mídias. Um exemplo bem significativo do forte impacto da mídia e demais tecnologias da informação pode ser observado no Desenho 1.

Desenho 1 - Produção de uma criança participante da pesquisa com idade 8 anos

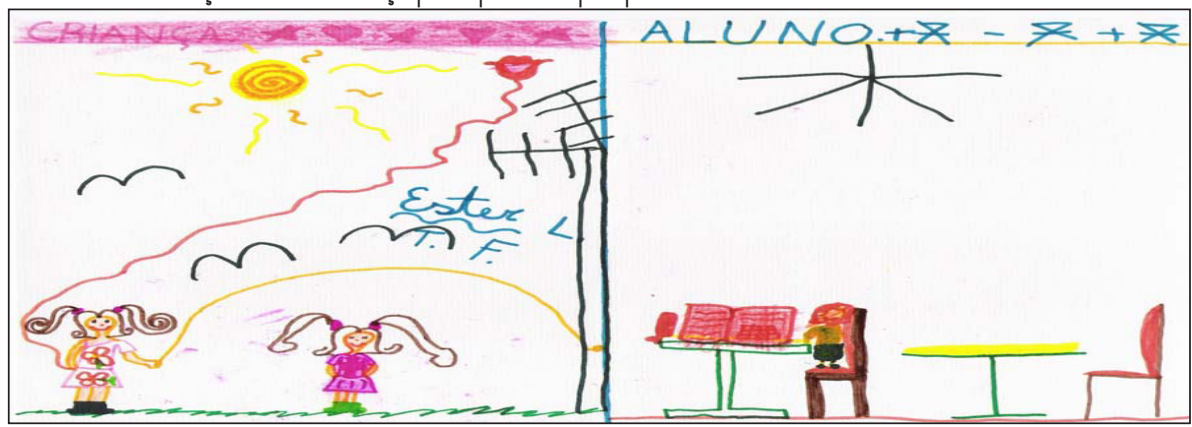

Fonte: os autores.

Inegavelmente, o desenho da E2 é um indício de que a televisão intervém na brincadeira da criança e na sua cultura lúdica, entendendo o brincar, na ótica Brougère (2004), como um espaço de criação cultural por excelência. Brougère (2004, p. 14) ressalta que o brinquedo, como construção social, "é um produto nascido do comércio, usado pela criança e reconhecido pelo adulto", isto é, determinados brinquedos só serão utilizados pelas crianças com o consentimento dos pais. Nesse sentido, certos brinquedos limitam o brincar e as relações entre as crianças, impedindo ações inovadoras e as descobertas de transições importantes no seu processo de desenvolvimento, que, segundo Prout (2004), só ocorrem coletivamente.

Nossas sociedades que desenvolveram o divertimento [...] parecem nossas sociedades que desenvolveram o divertimento [...] parecem despreparadas para compreendê-lo, ainda mais quando se trata de crianças naturalmente destinadas à educação generalizada para se tornarem adultos. (BROUGĖRE, 2004, p. 333).

Segundo Benjamin (2002, p. 72), o brinquedo é um confronto entre a criança e o adulto, porém, muito mais do adulto do que da criança. A afirmação desse autor parte da seguinte premissa: "pois de quem a criança recebe primeiramente seus brinquedos se não deles?" Resta, assim, para a criança, usar de sua imaginação e transformar todo e qualquer objeto em brinquedo, como o representado no Desenho 2, a seguir. 
Desenho 2 - Representação de um dos participantes da pesquisa com idade 7 anos

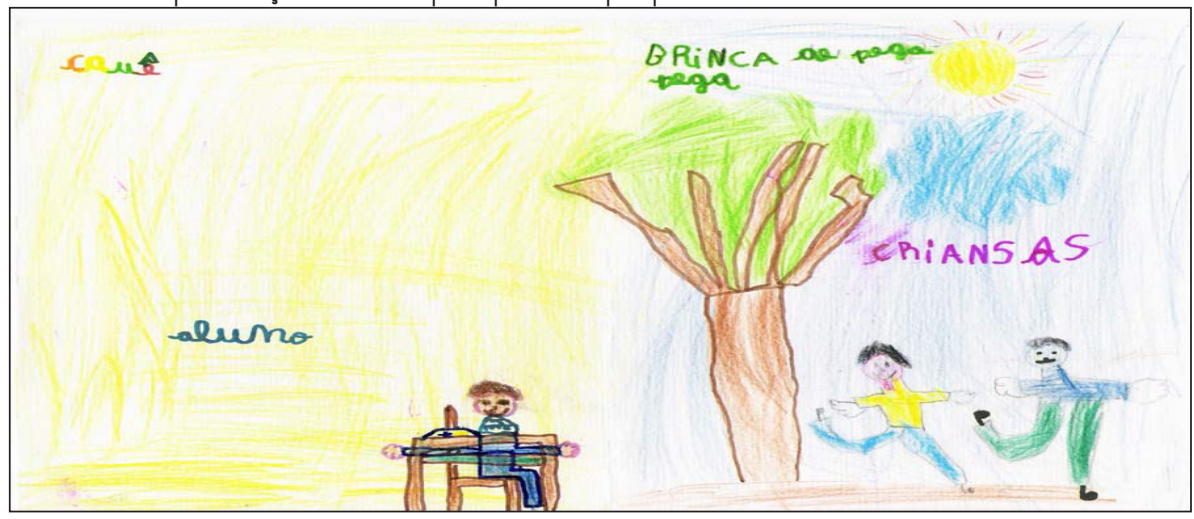

Fonte: os autores.

Quando se expressaram verbalmente, as crianças, protagonistas-participantes; desta pesquisa, manifestaram que brincavam no parque, de bola, bicicleta, de vídeo game, de correr, de amarelinha, de boneca, de soltar pipa, de dançar, de esconder, de cabra-cega, de cantar, de pular, de conversar, de desenhar, de contar histórias e de assistir à TV. Essas ações, provenientes de uma cultura própria das crianças, embora decorrentes da relação da cultura que as cerca, representam o que normalmente é designado como atividades livres, como momentos regulados pelas próprias crianças.

Considerando a dinamicidade e a diversidade de atividades realizadas pelas crianças, o processo de escolarização apresenta-se, para elas, como um grande desafio, enquanto movimento constante de ruptura e de acomodação, em face da regulação do tempo e do tipo de atividade estabelecida pelo professor, na sala de aula. Cabe destacar, especialmente, as atividades de aprendizagem realizadas, pelas crianças, individualmente ou em pequenos grupos, permanentemente, sob o olhar do adulto.

Nesse sentido, evidencia-se nesse movimento das crianças o reconhecimento da existência de uma cultura própria da escola que conforma, de uma maneira muito particular, o ofício de ser aluno. 0 modo como a escola se organiza e opera, via currículo, reforça os mecanismos de adaptação, que perpassam todas as ações do cotidiano escolar (VIÑO FRAG0, 2000).

Valemo-nos das observações e das falas das crianças registradas durante as rodas de conversa com o intuito de reafirmar como esse movimento de ruptura e de acomodação, o entrelugar, está presente na escola: Episódio 1 - Narrado por E4: 
Na sala de aula, enquanto a professora explicava as atividades no quadro, eu na minha carteira, brincava com um boneco (Homem-Aranha). A professora, ao perceber, disse: "Gabriel, guarda já esse brinquedo, porque durante as aulas a gente já combinou que não dá para fazer atividade e brincar ao mesmo tempo". Aí eu guardei o boneco embaixo da carteira. A professora falou outra vez: "aí não, porque você pode ter a tentação de pegar. Guarda dentro da mochila".

Tanto o sistema educacional como a instituição educativa, em sua cultura estabelecida, se expressam como um "conjunto de ideias, pautas e práticas relativamente consolidadas, como modo de hábitos." (VIÑA0 FRAG0, 1998, p. 169). Ainda nesse aspecto, segundo Bourdieu (1997), para dar conta dos seus fazeres, as instituições educativas organizam os espaços e os tempos de forma a enquadrarem seu sistema de regras ao sistema social determinante e, desta forma, constituir o sistema de habitus.

Em se tratando da constituição dos ofícios de criança e ofício de aluno, se faz necessário entrecruzar olhares sobre a infância e a educação, procurando ultrapassar a naturalização do ofício de aluno. Nas expressões das crianças, conforme é possível constatar nos desenhos de E4 e E5, a escola, locus da investigação, apresenta formas de controle e de dominação, levando-nos a inferir que as crianças "parecem acima de tudo assujeitadas e não sujeitos." (SARMENTO, 2004, p. 19).

Desenho 3 - Elaborado por um aluno participante da pesquisa com idade de 7 anos

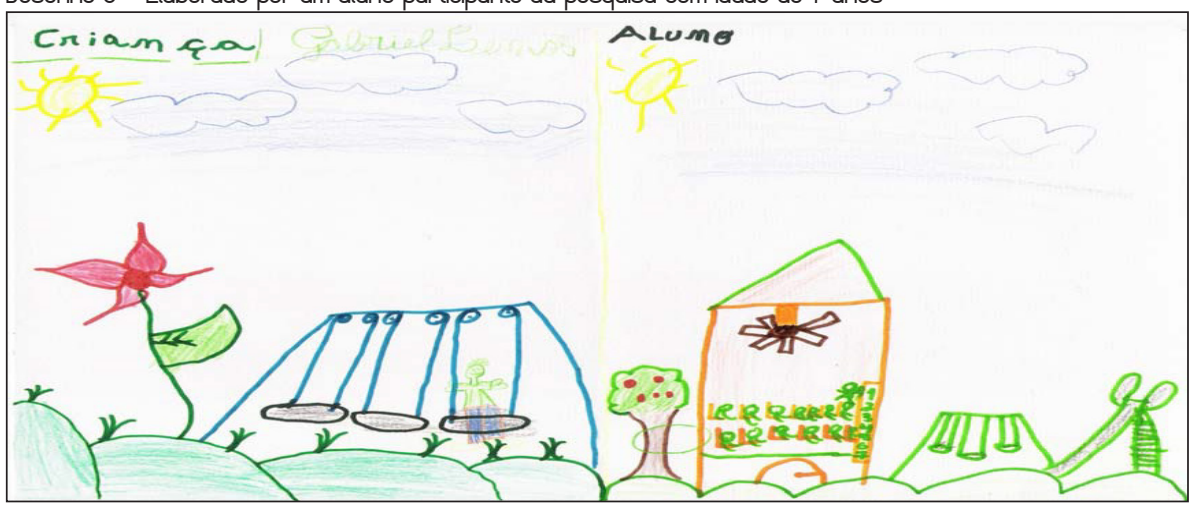

Fonte: os autores.

A E4 explicita claramente esse sentimento: aqui na escola é para estudar e não brincar. A gente estuda bastante né? A fala da E4, bem como de outras crianças, representa que, com efeito, nas interações em instituições educativas, há mais do que a constituição de perspectivas de um ofício. 0 s cenários educativos desvelam cenas em que pessoas, adultos 
e crianças se identificam e se reconhecem, mediante a expressão de competências gerais de ator social. Trata-se, então, de demonstrar o universo de significações revelado pelas crianças, no qual os adultos têm o poder de obrigá-las a escolher princípios e/ou valores que orientam suas ações.

Os desenhos, neste caso, incidem na existência de dois mundos distintos: em primeiro plano, o mundo institucionalizado, com adaptação às regras, às normas, horários, rotinas, espaços e tempos delimitados e hierarquizados, onde, segundo Foucault (2002), cada criança é definida pelo lugar que ocupa, pela posição na fila, pelas tarefas e provas, pois os lugares individuais tornam possíveis o controle de cada um e o trabalho simultâneo de todos os sujeitos, tal como se pode observar no Desenho 4.

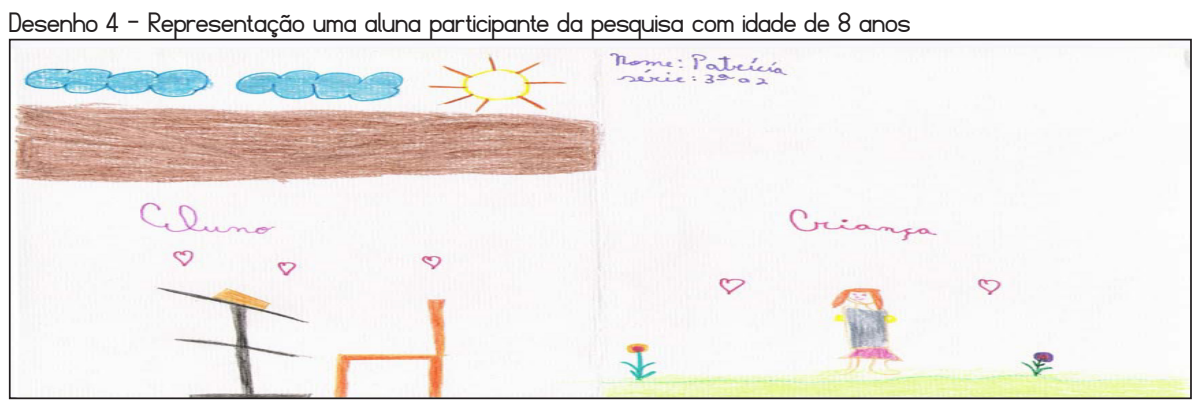

Fonte: os autores.

Algumas crianças, protagonistas desta pesquisa, fizeram também, em seus depoimentos, menções a determinados valores que são fortemente divulgados e inculcados pelos adultos. Arroyo (2000, p. 239) chama a atenção para o discurso escolar das elites que: "prometem à infância que a escolarização thes trará inexoravelmente o progresso, o emprego, uma vida melhor." Principalmente nos espaços educativos, referencia-se a escola como um lugar que as instrumentalizará para a conquista de um futuro melhor quando adultos. Destaca-se, nesse caso, um fragmento da conversa com E4, E5, E6, por ser revelador do sonho de ascensão social que é manifestado pelas famílias e legitimado na escola.

- Pesquisador(es): sua mãe trabalha?

- E4: sim, desde as 7 horas, vende plástico.

- Pesquisador(es): e seu pai?

- E4: ele vende coisas de dentista. 
- Pesquisador(es): você mora em casa ou apartamento?

- E4: eu tenho casa normal.

- Pesquisador(es): o que é uma casa normal?

- E4: assim, normal...

- E5: Você sabia, E4 que hoje o meu irmão ganhou uma nota de $\mathrm{R} \$ 100,00$ do meu pai?

- E6: Quanto dinheiro. Ele recebe mesada? Eu só tenho $\mathrm{R} \$ 20,00$ para comprar merenda. Só para a merenda. Meus pais ganham muito pouco. Por isso preciso estudar muito. 0 que o seu pai faz?

- E5: É construtor, ele faz casas pra gente morar.

- E4: Ele deve ganhar muito dinheiro. Será que ele é, assim... Engenheiro?

- E5: entende agora porque a gente aprende e depois a gente brinca?

- E6: porque estudar é mais importante para o nosso futuro.

- E6: eu acho que é mais importante para a professora, é mais importante ser aluno.

Desenho 5 - Elaborado por um aluno participante da pesquisa com idade de 8 anos

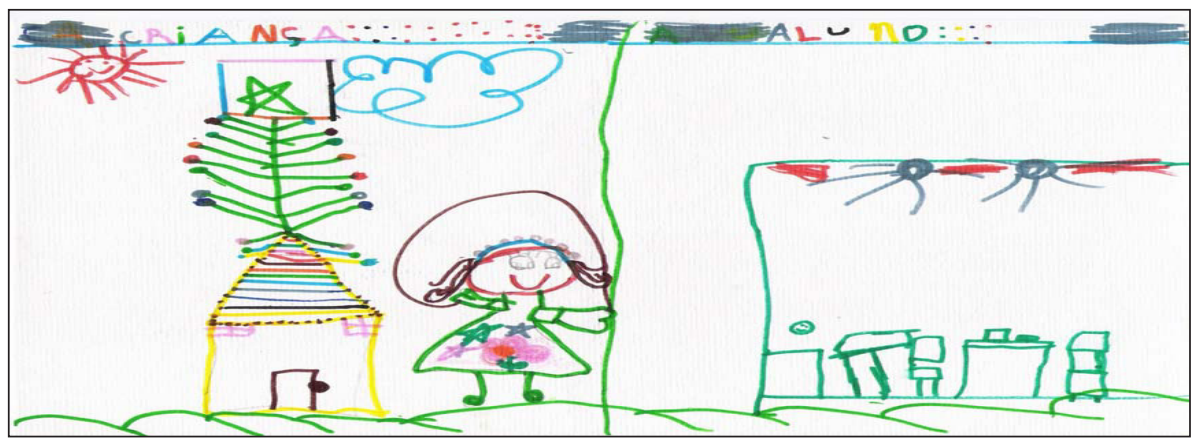

Fonte: os autores.

A inclusão das crianças em uma instituição oficial pública, como é a escola, regida por um conjunto de convenções, normas, programas, graus e saberes, funciona como códigos de permissão e interdição, fazendo com que cada um entenda como natural os muros que the são impostos ou a que estão submetidos. Essa questão pode ser visualizada no desenho 5, apresentado acima, demonstrando o universo de significações revelado pelas 
crianças. Esses códigos, em grande parte ainda desconhecidos pelas crianças, supõem a internalização de convenções para a constituição da categoria do ofício de alunos em paralelo ao ofício de criança.

A autora do desenho 6, a seguir, reconhece a existência desses dois ofícios distintos. Em primeiro plano, expressa as vivências no mundo institucionalizado com adaptação às regras, às normas, horários, rotinas, espaços e tempos delimitados e hierarquizados... Em segundo plano, representa o mundo plural da construção infantil com seus iguais, com seus brinquedos e brincadeiras, com suas vivências cotidianas fora do espaço institucionalizado.

Podemos inferir, nesse sentido, a grande contribuição crítica das crianças em face de suas manifestações expressivas; para que possamos perceber a relevância de um processo educativo que lhes assegure também, na escola, as vivências de seu ofício de crianças.

Desenho 6 - Expressão de uma aluna participante da pesquisa com idade de 8 anos

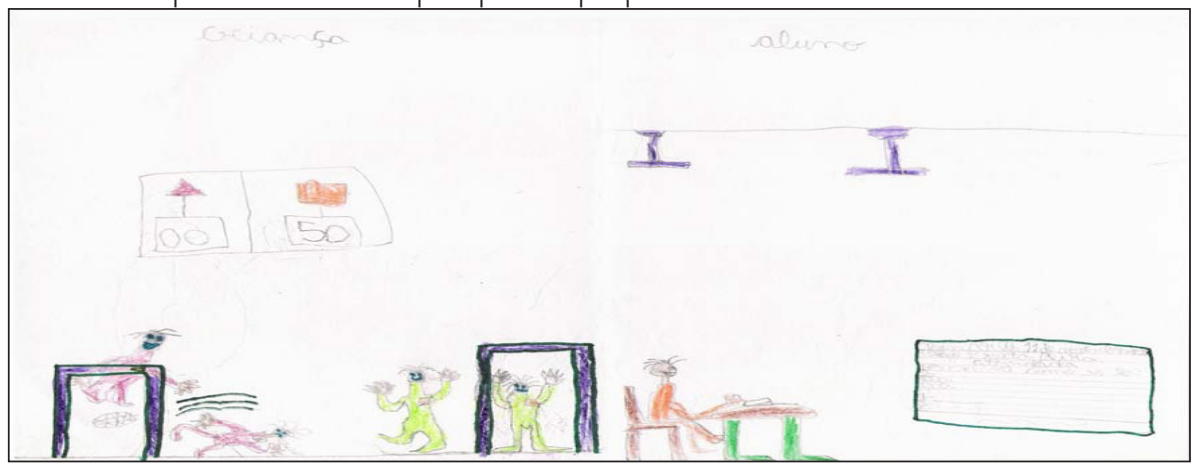

Fonte: os autores.

Os desenhos das crianças denotam que as regras implícitas nas maneiras de estar, mover-se, falar e atuar na escola são apreendidas no curso das interações estabelecidas entre adulto-criança, criança-criança, mediante sinais que constituem o que é "naturalmente" a escola, os lugares e momentos da vida escolar, aspectos que se evidenciaram durante as conversas com as crianças.

Nos dados empíricos, frequentemente houve indícios de que as crianças têm sua liberdade administrada e estão, desde sempre, inseridas num mundo regrado ao qual elas, gradativamente, devem se submeter, e delas se espera e se exige cada vez mais sentido à regra e à hierarquia. Ainda com relação à hierarquização dos lugares ocupados pelos interlocutores, Carvalho (1997, p. 171) assinala que "a professora é, na dinâmica discursiva, a 
representante autorizada da escola e da sociedade. A ela é atribuído não só o poder, mas a responsabilidade de instaurar e assegurar as relações de ensino na sala de aula."

Esteban (2004), em seu posicionamento, chama a nossa atenção para que a educação escolar não seja demarcada por ações que enfatizem somente a transmissão e a reprodução de conhecimentos, impedindo e/ou dificultando o diálogo entre os atores sociais circunscritos ao cotidiano escolar, especificamente as crianças. Atos inscritos na dinâmica do conhecimento que têm a ordem, a regra e a hierarquia como norte instauram procedimentos que silenciam e expressam a impossibilidade de ruptura necessária para que a criança possa viver plenamente a sua infância também na escola. 0 silenciamento das crianças está vinculado a processos sociais hierarquizados, nos quais se diz que "os professores impõem aos alunos normas tão rígidas quanto aquelas a que estão submetidas, tendo os pais como seus fiadores." (GUIMARÃES, 2003, p. 63).

\section{CONSIDERAÇÕES FINAIS}

Rememorando os passos do processo investigativo, na tentativa de encontrar respostas para o problema formulado e, assim, alcançar o objetivo proposto, voltamos ao procedimento inicial, caracterizado pelo fato de selecionar os interlocutores para a constituição do espelho teórico como fundamento da pesquisa, pressupondo a relação na constituição da infância com os ofícios de criança e de aluno.

0 material, objeto de análise e interpretação (desenhos, conversas, observações, registros e notas), foi produzido no interior da instituição educativa. A produção dos dados ocorreu considerando a criança na condição de aluno, cuja representação da escola surge como instituição separada do lugar da casa, da família e de outros espaços, caracterizando, desta forma, os limites da análise.

A investigação também não teve a pretensão de defender uma cultura específica da infância independente da cultura do adulto ou advogar a existência de uma única cultura infantil, de uma cultura singular da infância, mas mostrar que nas relações sociais as culturas escolar, infantis e adultas se interpenetram, produzindo, além da interdependência dessas culturas, os marcos divisórios de como, onde e quando elas são constituídas.

Pela natureza desta investigação, esperamos, de alguma forma, contribuir com o processo de formação inicial e continuada de professores que atuam na educação da infância, especialmente, os professores de crianças em processo de alfabetização, a fim de que possam perceber nas expressões das crianças e em suas vozes outras leituras e olhares sobre a experiência vivida por elas no contexto escolar. Assim, estarão mais atentas 
"ao desconhecido que chama a nossa porta." (DELEUZE, 1990, p. 160). Acreditamos, como Kohan (2001 p. 8), que "apenas com a ajuda de um pessoal adequado poderemos conseguir que o mundo inteiro volte à infância."

Mediante as manifestações das crianças, ficou claro que elas sabem que estão em um lugar com diferentes fazeres, qual seja, a escola, que thes impõe o ofício de alunos o tempo inteiro, embora, na escola, elas almejem também um tempo para exercerem o seu ofício de crianças, querendo brincar, desenhar, cantar, conversar, movimentar-se, transgredir regras e normas, num exercício constante de não-submissão.

É essa busca constante que se constitui o que defendemos como um "entrelugar". Por isso, nossa preocupação em conhecer o ponto de vista das crianças sobre a experiência de ser criança e de ser aluno tendo como referência uma escola pública, lembrando que a infância precisa ser compreendida na sua singularidade e as crianças, como atores sociais plenos. Acreditamos que as vozes e os desenhos das crianças apresentados nesta investigação servem de mapas e/ou bússolas para indicar que as crianças não se limitam a reproduzir o mundo do pequeno à sua escala, mas pelo avesso, em mostrar seu modo de pensar, expressar e sentir como agentes sociais e culturais.

\section{REFERÊNCIAS}

ARFOUILLOUX, J. C. A entrevista com a criança: abordagem da criança através do diálogo, do brinquedo e do desenho. Rio de Janeiro: Zahar Editores, 1983.

ARROYO, M. G. Oficio de mestre: imagens e auto-imagens. Petrópolis: Vozes, 2000.

BARROS, A. J. P. Projeto de pesquisa: propostas metodológicas. Petrópolis: Vozes, 1990.

BENJAMIN, W. Reflexões: a criança, o brinquedo e a educação. 34. ed. São Paulo: Duas Cidades, 2002.

BHABHA, H. K. 0 local da cultura. 3. ed. Belo Horizonte: Universidade Federal de Minas Gerais, 2005.

BOURDIEU, P. Razões práticas sobre a teoria da acção. Oeiras: Celta, 1997.

BROUGĖRE, G. Brinquedos e companhia. São Paulo: Cortez, 2004.

CARVALHO, N. C. Lúdico: sujeito proibido de entrar na escola. Revista Motrivivência, Florianópolis: UFSC, v. 1, n. 9, p. 1-8, jan./jun.1997.

DELEUZE, G.; GUATTARI, F. Mil platôs: capitalismo e esquizofrenia. Rio de Janeiro: Ed. 34, 2011.

DELEUZE, G. ¿̇ue és un dispositivo? In: DELEUZE, G. Michel Foucault, filósofo. Barcelona: Gedisa, 1990. p. $155-161$. 
DERDYK, E. Formas de pensar o desenho: desenvolvimento do grafismo infantil. 3. ed. São Paulo, Scipione, 2004.

ESTEBAN, M. T. Escolas que somem, reflexões sobre escola pública e educação popular. Revista Perspectiva, Florianópolis, v. 22, n. 1, p. 127-144, jan./jun. 2004.

FARIA, A. L. et al. Por uma cultura da infância: metodologias de pesquisa com crianças. Lisboa: Autores Associados, 2002.

FARIA, A. L. G. de; DEMARTINI, Z.; PRADO, P. (org.). Por uma cultura da Infância: metodologia de pesquisa com crianças. 3. ed. Campinas: Autores Associados, 2009. v. 1.

FOUCAULT, M. Vigiar e punir: nascimento da prisão. 25. ed. Petrópolis: Vozes, 2002.

FRANGE, L. B. P. Por que se esconde a violeta? São Paulo: Annablume; Uberlândia: Universidade Federal de Uberlândia, 1995.

GOBBI, M. A. Desenho infantil e oralidade: instrumentos de pesquisa com crianças pequenas. In: DEMARTINI, Z; PRADO, P. D.; FARIA, A. L. (org.). Por uma cultura da infância: por uma metodologia de pesquisa com crianças. Campinas: Editora Autores Associados, 2002.

GOBBI, M. A. Mundos na ponta do lápis: desenhos de crianças pequenas ou de como estranhar o familiar quando o assunto é criação infantil. Linhas Críticas, Brasília, DF, v. 20, n. 41, p. 147-165, jan./abr. 2014.

GUIMARÃES, Á. M. Vigilância, punição e depredação escolar. 3. ed. Campinas: Papirus, 2003.

GUSMÃO, N. M. M. Para desatar fios e descobrir desafios. Revista Proposições, São Paulo, v. 26, n. 3, p. 65-68, nov./dez. 1997.

GUSMÃO, N. M. M. Linguagem, cultura e alteridade: imagens do outro. Cadernos de Pesquisa, São Paulo, v. 1, n. 107, p. 41-78, jul./ago. 1999.

KISHIMOTO, T. M. 0 jogo e a educação infantil. São Paulo: Pioneira, 1998.

KOHAN, W. O. A infância como figura de emancipação. In: ANPED, 24., 2001, Caxambu. Anais [...] Caxambu, 2001.

LARA, A. M. B.; MOLINA, A. A. Pesquisa Qualitativa: apontamentos, conceitos e tipologias. In: TOLEDO, C. A. A.; GONZAGA, M. T. C. (org.). Metodologia e técnicas de pesquisa nas áreas de ciências humanas. Maringá: EEduem, 2011. p. 121-172.

LEITE, M. I. F. P. Desenho infantil: questões e práticas polêmicas. In: KRAMER, S.; LEITE, M. I. (org.). Infância e produção cultural. São Paulo: Papirus, 1998. 
LEITE, M. I. F. P. 0 que e como desenham as crianças? Refletindo sobre condições de produção cultural da infância. 2001. १८ p. Tese (Doutorado em Educação, Sociedade e Cultura) - Faculdade de Educação, Universidade Estadual de Campinas, Campinas, 2001.

MALAGUZZI, L. História, idéias e filosofia básica. In: EDWARDS, C.; GANDINI, L.; FORMAN, G. (org.). As cem linguagens da criança: a abordagem da Reggio Emília na educação da primeira infância. Porto Alegre: Artes Médicas, 1999. p. 59-104.

MARTINS, M. C. F. D. Não sei desenhar. 1992. 200 p. Dissertação (Mestrado em Artes visuais) - Instituto de Artes, Universidade Estadual Paulista Júlio de Mesquita Filho, São Paulo, 1992.

MATOS, M. Narra-Grafias de viagem. In: CLARA, F. et. al. Várias Viagens: estudos oferecidos a Alfred Opitz. Portugal: Famalicão, Edições Húmus, v. 1. n. 1. p. 263-288, set./dez. 2011.

MOREIRA, A. A. 0 espaço do desenho: a educação do educador. 9. ed. São Paulo: Loyola, 2018.

PINTO, M.; SARMENTO, M. J. As crianças: contextos e identidades. Braga, Portugal: Centro de estudos da criança, 1997.

PROUT, A. Reconsiderar a sociologia da infância: para um estudo interdisciplinar das crianças. Comunicação Proferida por ocasião do ciclo de conferências em sociologia da infância. Tradução: Helena Antunes. Portugal: UM-IEC, 2004.

SARMENTO, M. J. 0 estudo de caso etnográfico em educação. In: ZAGO, N. et al. Itinerários de pesquisa: perspectivas qualitativas em sociologia da educação. Rio de Janeiro: DP\&A, 2003. cap. 2, p. 137-179.

SARMENTO, M. J. 0 estudo de caso etnográfico em educação. In: ZAGO, N. et al. Itinerários de pesquisa: perspectivas qualitativas em sociologia da educação. Rio de Janeiro: DP\&A, 2004. p. 137-179.

VIÑAO FRAGO, A. El espacio y el tiempo escolares como objecto histórico. Contemporaneidade e Educação. Revista Brasileira de Educação, v. 5, n. 27, p. 93-110, set./dez. 2000.

VIÑAO FRAGO, A. Tiempos escolares, tiempos sociales. Barcelona: Editorial Ariel Practicum, 1998.

Endereço para correspondência: Rua Joaquim Fabio de Souza, 57, Itapema do Norte, 89249-000, Itapoá, Santa Catarina, Brasil; luizmartins.jr@hotmail.com 